\title{
Dialogic education: reflections from an accounting course
}

\section{Melina M. Manochin* and Stuart Cooper}

\author{
Finance and Accounting Group, \\ Aston Business School, \\ B4 7ET, UK \\ E-mail:m.m.manochin@aston.ac.uk \\ E-mail: s.m.cooper@bristol.ac.uk \\ *Corresponding author
}

\begin{abstract}
Our paper aims to contribute to the growing body of literature that has suggested that tertiary accounting education should not simply transfer technical/functional/vocational accounting knowledge. This literature suggests that a more critical accounting educational content complemented by a more dialogical teaching approach is more appropriate. Our paper provides further reflections on just such a course and the challenges that this raises. Specifically, it comments on learner resistance and engagement, syllabus design, delivery and assessment methods. In addition, this paper introduces the role that theory, secondary research and debates have played in this course. The value of this type of course, in terms of developing and transforming the learners is discussed.
\end{abstract}

Keywords: dialogic education; accounting course; learning process.

Reference to this paper should be made as follows: Manochin, M.M. and Cooper, S. (xxxx) 'Dialogic education: reflections from an accounting course', Int. J. Critical Accounting, Vol. X, No. Y, pp.000-000.

Biographical notes: Melina M. Manochin is a Lecturer of Accounting at the Aston Business School. Her research interests include accounting pedagogy, management control and interdisciplinary perspectives on accounting.

Stuart Cooper is a Professor of Accounting at the University of Bristol. Until 2013, he was a Senior Lecturer at Aston Business School. He is a member of the ICAEW and his primary research interests are in the areas of social and environmental accounting and accountability.

\section{Introduction}

Our study reflects upon a research-tutored undergraduate course, which has developed on the premise that accounting practices and relations of accountability and control should be critically studied in their organisational and social context rather than in a strictly economic domain (Hopwood, 1983). However, contemporary textbook accounting practices and accounting educational curricula draw heavily on the economic tradition while accounting professional training maintains the perceived usefulness of quantification (Laughlin, 1987). Our paper contributes to the growing body of literature 
(which is reviewed in detail in the next section of this paper) that has suggested that tertiary accounting education should not simply transfer technical/functional/vocational accounting knowledge. This literature suggests that a critical accounting educational content complemented by a more dialogical approach is more appropriate. The critical and dialogical approach suggested in these papers [see in particular Thomson and Bebbington (2004) for a valuable discussion] often refer to, and are inspired by, the writings of Freire $(1993,1998)$ and this is also true for our paper.

In the light of Freire's advocacy and the need to enable a transformative dialogue to aid a fruitful learning process in accounting education, we look at the potentialities of dialogic education in the literature and in our course. The course's key aim is to encourage each learner to question and address the role of accounting and/or accountants in contemporary organisations and to discuss issues of organisational control and accountability in the light of their own placement year experience and academic literature. In this paper, aspects of this learning process and the possibilities/constraints of such an educational perspective within accounting higher education are discussed. Our study includes interviews with current and alumni students, educators and a senior administrator. The evidence of this study is based on experiences and reflections of our informants and provides an insight into the potentialities of such a course in university accounting. Such potentialities are identified as the emotional and intellectual transformation of final year accounting students that help them realise and address their role in their future careers in accounting's complex organisational context.

This paper develops in the following stages. The following section reviews the literature, which has critiqued current banking style accounting education and has championed a more critical and dialogic approach. Then we discuss our methodological considerations in undertaking this research and provide further information about the course being considered here. The analysis and discussion of our research follow while potential conclusions and limitations of our study are disclosed.

\subsection{Dialogic education}

Freire (1993, 1998) had an “abhorrence of neoliberalism” (1998, p.22) and was extremely critical of the inequalities and oppression that result from the "intrinsically evil" (1998, p.114) capitalist system. For him, many current educational systems and practices do not problematise the current system that enables poverty and deprivation alongside a class of "haves" for whom "money is the measure of all things, and profit the primary goal" (1993, p.40). Part of the problem is the "banking concept of education" whereby "the teacher issues communiqués and makes deposits which the students patiently receive, memorize, and repeat” (1993, p.53). Further, he (1993) argues that this type of education "attempts to control thinking and action" (p.58) and "directly or indirectly reinforces men's fatalistic perception of their situation” (p.66). Banking education, therefore, is an important part of an oppressive system and "serves the interests of the oppressors, who care neither to have the world revealed nor to see it transformed" (p.54).

In contrast, Freire advocates a 'problem-posing' form of education, which develops people's "power to perceive actually the way they exist in the world ...[and] come to see the world not as a static reality, but as a reality in process, in transformation" (1993, p.64). In this form of education students are no longer passive, docile receptacles, but rather are "critical co-investigators in dialogue with the teacher" (p.62). This form of education enables "true learning” and insists "on the critical capacity, curiosity, and 
autonomy of the learner", who "will be engaged in a continuous transformation" (1998, p.33). Central to problem-posing education is that both the teacher and the student have an open approach, which accepts that all humans (including even teachers!) are unfinished and incomplete and hence are permanently searching and learning. For Freire this searching and re-searching is a permanent process for learners and is central to their development and transformation. Further, he (1998, p.35) suggests there can be no teaching and no learning without research and vice versa. In this view, learning is a self transformative process for both the educator and the student. To teach means to create the possibilities for the production or construction of knowledge, and to research means to explore the countless possibilities of knowledge with methodical curiosity and reflection. In such an interplay the educator becomes the leading learner in a continuous learning process; while the students are seen as knowable actors that while being made aware of their conditions of existence, feedback their experiences in an on-going transformative learning process.

Another essential feature of Freire's educational practice is the need for communication, not communiqués, and dialogue, which:

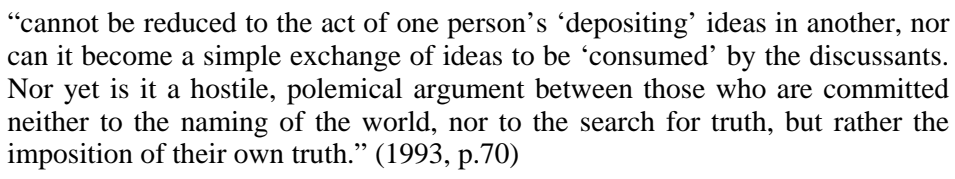

Freire (1998) insists that transformative learning involves dialogue between all learners involved in the process. As Freire (1998) explains the reciprocal learning is what gives educational practice its gnostic character. Dialogue, for Freire, requires humility, openness, curiosity and an engagement in critical thinking. Through a dialogic approach the teacher and student engage in "open, curious questioning" (1998, p.81) with this process helping the student "to produce his or her own comprehension of the object in question" (p.106). This does not mean that there is no need for the teacher to "set forth his/her understanding and knowledge of the object” (p.81), but in this process the teacher must recognise the student's autonomy, which Freire (1998, p.98) suggests is "a process of becoming oneself, a process of maturing, of coming to be”.

Freire (1993, p.76) suggests that educational content should start from the "present, existential, concrete situation" of the people and should reflect their aspirations. Specific content should be a discovered and investigated within "generative themes", which relate to "ideas, values, concepts, and hopes" (p.82) either globally or for a particular society. Part of the educational process should be to identify, with the students, the relevant themes, the links between them and "pose these as problems" (p.89) for dialogical consideration. Freire (1993, p.84) considers "the fundamental theme of our epoch to be that of domination - which implies its opposite, the theme of liberation, as the objective to be achieved". In such a process both the educator and the students engage with research while they explore the possibilities of knowledge raised from limit-situations, which are at the "frontier between being and being more human", but serve some (oppressors) who "act to maintain the status quo” (p.83). 


\section{Critical accounting education and weak dialogics}

Accounting is a social construction of the capitalist system and acts as a technology of capitalism and its related ideology (Tinker, 1985; Dillard, 1991). Critical accounting critiques and seeks to transform this current social order (Dillard, 1991). Much contemporary accounting education, however, simply reflects this current social construction and is often reduced to a form of technical training. This educational practice has also been critiqued on a number of occasions (see for example, Boyce, 2004; McPhail, 2004). Specific criticisms include its capture by "managerialist forces" (Thomson and Bebbington, 2004) and its commodification "to produce compliant hegemonic technicians" [Saravanamuthu, (2004), p.600]. Accounting education's failure to problematise accounting's wider political and social role, but merely transfer knowledge of techniques to receptive students is quite clearly a form of banking education. Such education does not question how the "dominant forms of accounting promote, naturalise and universalise economically rational, profit-centred, corporatist values" [Boyce, (2004), p.572]. Therefore, this form of teaching does not develop the critical capacity, curiosity and autonomy of the learner. Day et al. (2003) suggest that as teachers and researchers accounting educators should be reflective about the students' engagement in their learning of critical accounting - as the purpose of learning critical accounting is to expose the conflicts, ideologies and complexities embedded in accounting practice. The necessity of critical accounting education becomes even more apparent considering the evolving role of accounting professionals (Parker, 2001) and recent corporate scandals (Cuganesan et al., 1997; Low et al., 2008).

Thomson and Bebbington (2004) acknowledge that there is a vast difference between the context of Freire's work and those of accounting educationalists working in UK higher education. They do not claim, therefore, that developments in their own teaching praxis provide students with a completely dialogic programme or course. For example, in Freire's work he advocates the involvement of students in the course design from the very outset. Involving the students in this way ensures the relevance of the themes and issues of the course and is an important part of the dialogical process. Following this model of course design in its purest form within the UK higher education system is, at the very least, problematic. Deadlines for course outlines are required in advance of courses starting and so, at this point, it is extremely difficult to include future students. For Thompson and Bebbington (2004) two partial solutions to this are to involve past students in the continuing evolution and design of the course and to leave room within the course for students to make choices as to the content of most relevance to them. Coulson and Thomson (2006) are also keenly aware that their own course would not be considered dialogical in the purest sense of Freire's work. They categorise their own course as 'weak dialogic' given that it does not fully satisfy "a number of dialogic criteria" (p.262) including the inability to involve students in the design of the course. We are much taken by this phrase and conceive an educational practice continuum that moves from a fully banking education at one extreme to a purely dialogic education at the other. In such a conception it is possible to visualise the initiatives discussed in the following subsection as steps that help to move along this continuum away from the extreme of banking educational practice and therefore towards a more dialogical approach. 


\title{
2.1 Weak dialogical initiatives in accounting education
}

A number of accounting educationalists have been inspired by the work of Freire and have henceforth reformed aspects of their practice. One such example is Thomson and Bebbington (2004, p.615) who have attempted to "minimise the impact of a tendency towards banking education and have sought to build dialogical elements in to accounting classes”. The three key changes that they have developed in their own teaching include joint responsibility with the students, increased use of 'practical elements' (p.617) and a greater consideration of issues that will have more specific relevance to the students and their experiences. For them a particularly successful initiative has been the use of problem-posing classes within courses (Thomson and Bebbington, 2004). They have achieved this through the use of case studies that have been chosen with regard to the student's own experiences so its relevance to the 'real world' is apparent. Such case studies, they argue, do not necessarily need to be of a critical nature, but can cover “"conventional' material (including topics covered by accreditation) in a dialogic fashion” (p.618). As such they argue that actually the method/process of teaching is 'equally important' as the content. For them the dialogical approach is a powerful educational approach that can transform lives.

To return to the difficulty of including student's in course design we noted earlier Thomson and Bebbington's (2004) suggestion that past students can be involved and space can be left for student choices to be made. Coulson and Thomson (2006) have consciously allowed students' choice within the assessments that they undertake. From choice of book to review, to essay topic, to company to shadow account the students are allowed to take a greater involvement than would often be the case more traditionally. The benefit of this approach is to enable the students to make selections that are more relevant to their own experiences. More broadly Coulson and Thomson (2006) identify the importance of the assessment process within a dialogical approach. Of great importance is that the assessment itself should not reward a student for remembering material that the students have received and banked, as this will encourage a receptive and passive approach to learning. They continue that if the assessments are not correctly aligned with the dialogic learning activities, then the complete learning experience "can be diminished” (p.271). On their course:

\begin{abstract}
“Students were 'rewarded' for proposing alternative solutions, innovative and/or creative thinking, informed critiques, original insights, methods of gathering evidence, quality of the evidence, discussing obstacles to change, integrating material from non-accounting sources, critique of existing theory and practices, drawing on their experiences, challenging existing perceptions, alternative modes of presenting their material. Marks were also available for important academic attributes, such as use of literature, intellectual coherence, quality of writing, structure of argument and factual analysis.” (p.268)
\end{abstract}

By definition an important part of a dialogical approach to education is to foster opportunities and space for dialogue to occur. Coulson and Thompson (2006) stress the importance of allowing students and the teacher to provide their own representations to the class and to listen to the representations of others. But this is not an end in itself, as dialogic encounters require critical reflection and reconsideration of these representations. If this space does not encourage dialogue, but rather results in polemical arguments of participants holding intransigent positions then a dialogical encounter has not been achieved. Instead the participants are talking past each other. They may 
well hear the words that others speak, but they are not truly listening and critically reflecting upon them. For Coulson and Thomson it is important that the approach taken encourages "a systematic, transdisciplinary approach to problem formulation and solution recognition” (p.267).

In a different initiative, Boyce (2004) advocates that accounting education should move away from simply teaching core accounting techniques and he would rather see broader, more tangential themes being explored. He argues that the consideration of such tangents will actually enable a more "meaningful and comprehensive consideration of accounting itself” (p.574) and that such an approach "presents the ideal opportunity for the kind of dialogical education advocated be Freire” (p.575).

\subsection{Challenges to weak dialogical initiatives}

Boyce (2004) does suggest, however, that applying such an approach within accounting courses can have certain problems associated with them. First, these courses tend to be optional and so only reach a relatively small proportion of students, who through selfselection are already likely to have an interest in the issues such a course will raise. A more positive aspect of this is that the dialogical approach would seem to most likely work well with a smaller number of students. In fact, Coulson and Thomson (2006, p.271) suggest that this is a 'critical design issue' and they felt that 48 students was "around the upper limit that could be accommodated by this course design and allocated resources”. Clearly larger student numbers would pose a significant challenge to a dialogic approach unless appropriate resources could be provided.

A second challenge is that such a course will tend to meet with resistance from both students and academic colleagues. Boyce (2004) identifies that students at least initially may not appreciate the course, as material that challenges the status quo can be upsetting and this will be resented. This resistance was also seen as a challenge by Thomson and Bebbington (2004). They recognised that many students that choose to study accounting have done so for "extrinsic motivations" (p.617). Such students see accounting as a lucrative future career that requires knowledge of a set of techniques and analytical skills. Any course that does not appear to provide such knowledge and skills in an immediate and direct way will not match their expectations and will meet with resistance (see also Tinker and Koutsoumadi, 1997).

Thomson and Bebbington (2004, p.617) consider this instrumental student attitude as part of the broader challenge, which is that the "demand for accounting degrees, to a greater or lesser extent, is linked to the demand for accountants in the economy". Another challenging aspect of this relationship with the accounting profession is the professional training required and the related accreditation of accounting degrees. In order to achieve accreditation courses are required to include specified content and to meet specified assessment criteria. They feel that the content can be dealt with more easily, but the requirement for $70 \%$ of a course's assessment to be through closed book examinations is not sympathetic with the assessment criteria that is more appropriate for dialogic approaches (as discussed earlier). They also identify the difficulties that university systems and 'quality processes' can cause for more dialogical courses (Biggs, 2003; Moon, 2004). As discussed earlier, course and assessment design would ideally be created through dialogue with current students. University systems, however, require information on content and assessment in advance of a course running. 


\subsection{Potentialities of weak dialogical initiatives in accounting education}

Thus far our paper has identified a number of weak dialogic initiatives from within the accounting literature. The papers reviewed here have all reflected upon dialogic approaches to accounting education and the potential it has to develop and transform students. It has been argued that the dialogic approach has the potential to problematise managerialism and to critique capitalist society (Thomson and Bebbington, 2004; Boyce, 2004). Perhaps, ironically James (2008) drawing on Boyce (2004) argues that the accounting profession's desire for generic skills (for example interpersonal skills, critical thinking skills, organisational skills, and judgement) provides the case for a dialogical approach to accounting education. In particular James (2008) argues that a critical and dialogical course will provide students with a much greater opportunity to develop generic skills. Rather than passively receiving knowledge, as is the case in a banking education approach, a more dialogical approach requires greater involvement of students, who are required to interact with the materials and to reflect on their own knowledge and understanding.

Perhaps of particular relevance are skills relating to critical thinking and reflection (Race, 2005; Cottrell, 2005). Freire (1993) suggests that using generative themes within a dialogical approach should awake the learner's critical thinking (see also Kaidonis, 2004; James, 2008). For that reason the educator presents the generative theme material to the students for their consideration and invites them to express their own thoughts on the theme. Such practice may well result in unexpected directions being taken, but surprise for both the educator and the student is often an unavoidable but useful condition that could encourage students to experiment with their approach to critical reflection (Lucas, 2008). Critical and enquiring learning as a pedagogic condition for accounting education could enable self transformation and reflective understanding of the conditions where accounting occurs. Such critical learning requires action and reflection during the learning process, as both learners and the educator are called to engage in a dialogue and co-investigation (see also Kaidonis, 2004).

Transformative learning extends to the enhancement of critical thinking skills as well as to self awareness and confidence that enables engagement in professional practice. The main idea is that human beings and the world exist in constant interaction and it is in their capacity to intervene in praxis (reflection-action) (Freire, 1998). Educational challenges, as the ones embraced in the generative themes, may equip accounting graduates with an essential skill before they enter the complex world of businesses as the number of accounting scandals and ethical dilemmas is increasing alarmingly (Howieson, 2003; Saravanamuthu, 2004; Low et al., 2008; Burch, 2008)

For us, some key themes have emerged from this literature. First, we agree that the initiatives discussed in these papers (and subsequently in our own) are best described as a weak dialogical approach. Constraints within the UK higher education system and the relationship that University accounting education has with the accounting profession appear to preclude hopes for a more comprehensive dialogic approach. As discussed earlier we like to perceive these initiatives as steps on a continuum away from a banking education approach. The initiatives discussed in this section include the use of problemposing classes through case studies, allowing students space and choice and exploring broader tangential issues. Challenges relate to student numbers, resistance, professional accreditation, and assessment and these are issues that we will reflect upon throughout 
the remainder of this paper. The next section provides background information on the course upon which we are reflecting.

\section{The organisational and social context of accounting}

We have already argued that accounting education has been traditionally associated with and remains dominated by the teaching of analytical skills that reflect the link between early managerial studies with positivist classical economics. If we consider the research agenda we see that from the late 1960s/early 1970s a call has been made for a consideration of the wider organisational context of management accounting (Lowe, 1970). Such research has included behavioural and social influences on budgets (Argyris, 1969; Lowe, 1970) and managerial decisions on cost allocations (Caplan, 1966). Subsequently the research agenda has covered a wide breadth of aspects such as theoretical and methodological considerations (Bruns and DeCoster, 1969; Chua 1986; Cooper and Hopper; 1987; Laughlin, 1987).

The organisational context of management accounting thesis has become increasingly apparent in the research agenda and this forms the inspiration for our final year undergraduate course. The course runs during the academic year from early October to May and involves weekly class lectures and tutorials along with a range of assessments including two essays, group debates and a closed book written examination. The course is compulsory to final year specialist accounting students and can also be chosen as an elective by students from other final year undergraduate degree programmes. In recent years, the number of students enrolled on the course has varied between 95 and 125 . The student cohort is approximately equal in terms of gender and the vast majority of the students are in their early '20s. Approximately $30 \%$ of students are international for whom their first language is not English. The majority of students, but not all of them, will have experience of a one-year work placement, which they do in their third year.

The main three learning objectives inform all delivery and assessment activities and are as follows:

- to understand the use of management accounting as an accountability and control function within the wider organisational context

- to critically evaluate the assumptions behind management accounting/control theory and practice - seeing accounting processes through different 'theoretical lenses'

- to understand the importance of the behavioural, organisational, political, cultural and social aspects of management accounting/control.

The course draws on research published in academic journals and a wide reading list is provided early in the year. In addition, weekly core and optional reading is suggested on the Blackboard ${ }^{\mathrm{TM}}$ site of the course. We perceive the organisational context of management accounting as a meaningful thematic and it is from within this that a variety of generative themes have informed the course content as indicated in Table 1. 
Table 1 Generative themes - the organisational context of management accounting course outline

Introduction to management control and accountability: an unconventional perspective

Management control theory: studying management accounting in its organisational context

Alternative paradigms for management control and accountability:

- $\quad$ rational economic perspectives - the traditional view: agency theory and transaction cost economics

- the social construction perspective: cultural values in management control and accounting

- a critical perspective on power, organisational behaviour and management accounting

- $\quad$ post functionalism/postmodernism perspectives in managerial control and accountability

Management accounting change

Strategic management accounting

Risk management and control

Organisational trust and control/accountability

Control and accountability in public services: a governance perspective

Enterprise resource planning and strategic enterprise management

Sustainability and management control

Performance management

Environmental management accounting

Social and environmental reporting and sustainability

Divisional control and performance

Systems of control - an actor network theory perspective

Organisational learning, knowledge management and intellectual capital

This course curriculum is heavily influenced by the relevant research and so can be seen to be at the so-called 'research-teaching nexus'. The research-teaching nexus has been considered by Griffiths (2004) and extended by Healey (2005), who suggested that such teaching could be categorised as 'research-tutored', 'research-based', 'research-led' or 'research-oriented' (see also Jenkins et al., 2007; Malcolm, 2008). The categorisation is dependent upon whether the research content or process and problems is emphasised and whether students are seen as participants or as an audience. Although, we are uncomfortable with such categorisations we would on the whole suggest that this course is research-tutored as this emphasises research content and students as participants. Healey (2005) suggests that research-tutored courses are where discussion of research findings takes place in small groups and this is one of the key elements on this course.

The debate whether research is related to good teaching though has been rather curious. Although a number of studies suggest that good teaching does not necessarily depend on research (Hattie and Marsh, 1996; Robertson and Bond, 2005) others suggest that the link is profoundly positive and enhances students learning (Healey, 2005). It could be suggested that these studies rely on functionalist assumptions that place emphasis on the analysis of students' learning as statistical analysis of controlled samples of the population rather than the exploration of the inherent learning drive of those populations (Jenkins, 2004). 
With attention closer to the socially constructed learning experience of students, others suggest (Brew, 2003) that enquiring thinking processes and curiosity are essential conditions of learning and it should be encouraged as a potential recognition of the learner's own experience of the world (Cottrell, 2005; Race, 2005). As discussed earlier, Freire (1998) suggests there is no such a thing as teaching without research and research without teaching. On our course students are encouraged to develop an individually informed perspective on the role of accounting and accountants in contemporary organisations while researching in depth the literature on a subject of their choice that have been discussed in the thematic lectures using theories and case studies. Contact hours and activities accommodate dialogue and interaction between academics and students on an individual and group level. It is apparent that students very early in the course recognise that complex control and accountability matters in contemporary organisational contexts are not resolved with linear or financial only solutions but with the realisation that social, political and behavioural aspects need to be considered and understood. Therefore, to address fundamental questions on the role of accounting or accountants in such a context one should not look for 'one answer fits all' solutions but to seek understanding of contextual and behavioural aspects, and engage with a perspective for each case that enables for a unique insight. Such a perspective is enriched with the use of 'different theoretical lenses'.

\section{Research method}

The authors have now taught this course together for the last four years. Together we have critically reflected upon and discussed the course and whether and to what extent it achieves the objectives that it sets. These discussions and reflections are informed by our perception of the students' learning experience. Given the nature of the course we are often in dialogue with students concerning its contents, how it is run and assessed. More formally, the official feedback mechanisms of the university provide anonymous feedback about the course. Our reflections and discussions have resulted in the course changing over time, but the central ethos that the course is research-tutored and that it has the organisational context of management accounting as a meaningful thematic have remained constant. These reflections and discussions have been instrumental to our writing this paper.

In addition we decided to purposively study perceptions of this research-tutored course and its material and approach in terms of its impact on the learning and development of students. We wanted to engage in a "reflective dialogue with" [Cousin, (2009), p.154] final year current ${ }^{1}$ and alumni students of the course, academics who previously developed and delivered the course and an undergraduate office senior administrator $^{2}$ and this was achieved through face-to-face meetings with individuals or in two cases small groups of students. The invitation to participate in the research was sent to all current and alumni students for which contact details were available and ten students were kind enough to agree to give us their time and we are grateful to them. There was no attempt to deliberately select students from a particular background or experience of this course, although there is the possibility that there is a self-selection bias in those interviewed. We attempt to mitigate this by reflecting as much as possible on our experiences and other sources of feedback. In order to assist this reflection the authors have met regularly to reflect on and discuss our experiences with the course and 
any feedback received and this has been used to inform our paper. The conversations were conducted by both authors in line with the ethical research procedures and approval of the relevant committee of the university. An agenda was prepared for each conversation and included open ended questions that seek to enable discussion rather than lead and the interviewees were encouraged to contribute to the conversation in an informal manner. All conversations were digitally recorded, transcribed and analysed with NVivo 8.

The primary purpose for this research was to gather insights about the transformative learning potential of this course and explore the views of our informants and understand the impact of such course in their learning and our practice. In the sense that we would like to think that we are researching with our students and colleagues in order to change the course and so this study has elements of an action research methodology (Cousin, 2009). In short one purpose of our research was "to improve some aspect of the student learning experience” [Norton, (2009), p.xv], which is the purpose of pedagogical action research. By better understanding our students' learning and development so we hope to modify our own practice to enable this process further. The following section highlights our main insights into the challenges raised and the value of this course.

\section{The organisational context of management accounting: a weak dialogic learning process}

We noted from the earlier literature that there have been a number of initiatives within accounting education that have made progress in shifting away from a banking approach towards one which is more dialogical in nature. These initiatives involved using problem-posing classes, leaving space and enabling choices within courses and considerations of broader tangential issues. Also identified were a number of related challenges concerning student numbers, resistance, accreditation and assessment. Although not by design our own research identified themes relating to choice, case studies, resistance and assessment and these are discussed below. Student numbers and accreditation were not themes that came across strongly from our research material, but they are issues upon which we and our colleagues and the students have reflected. Student numbers are a concern as we want the course to be research-tutored and for it to enable dialogic encounters. In order to keep groups as small as possible a larger number of tutorials are held than is true for other courses of a similar size and this puts greater stress on the lecturer's time, but is considered essential to maintain the dialogic nature of the course. The content and assessment of this course is not consistent with the requirements of the professional accounting bodies and therefore it does not contribute in this way. As lecturers we are pleased that this is the case, as this means that we are not restrained in terms of content by accreditation and our colleagues have always been supportive of this position. Accounting students from this University do receive a number of exemptions from professional accounting exams, but generally courses are not designed specifically to achieve this. Clearly, if obtaining maximum professional accreditation for our students was a key factor in curriculum design, then it would not be possible to run this course in this way. This section now considers the key themes that have arisen from our research. 


\title{
5.1 A research-tutored undergraduate course
}

The organisational context of management accounting module is a final year taught course that draws on research themes and peer reviewed published academic articles (see Table 1). Early in the year students attend thematic lectures that draw on current research themes. These lectures are based on the idea that accounting practices have been traditionally seen through economic approaches and it is useful to consider the dimensions of control and accountability that are implicit in such practices. The usefulness of different theoretical lenses is discussed and links between practice and theory are introduced. After these thematic lectures, issues from the contemporary accounting research agenda (such as social and environmental sustainability, risk management, strategy, trust, management accounting change, performance management) are introduced and discussed during the weekly lectures, fortnightly tutorials in term 1 , weekly debates in term 2 and individual meetings with students as requested. Also in the second half of the course guest lectures from research active academics expand the scope of the on-going debates within these contemporary research themes.

The course differs in two very distinct ways from the other accounting modules that these students have encountered during their degree studies up to this point. Firstly, this course is research-tutored. This means, as noted above, that the course is driven by research within peer reviewed academic journal articles. Further, this course specifically uses the organisational context of management accounting as a meaningful thematic and the variety of generative themes consider alternative paradigms, perspectives and literature to the more technical material considered earlier in the students' degree programmes. Certainly in their earlier years of study, most accounting courses will draw heavily on a set textbook. One of the issues to which we will return to throughout the remainder of this paper is how this affects students' learning. The second distinction is that this is an accounting course without numbers. Throughout their earlier accounting studies the students have been taught the techniques of accounting that provide the answer. As one academic interviewee put it:

\begin{abstract}
"They think that accounting will be a subject that you can study at university where there are right and wrong answers... they like the certainty of doing number crunching problems. [In their earlier accounting studies] they are really learning a set of calculative techniques and they are coming to see management accounting practice as a purely kind of instrumental, rational, objective process. I think part of the function OCMA is to disabuse them of that notion.”
\end{abstract}

These distinctions require the students to undergo a considerable transformation throughout the academic year that relates to the level of engagement of all learners in the process, the interaction with other learners and the educators, the constructive dealing with emotions of surprise and the perceived self image link between that of an accounting graduate and a successful professional. The next sections look in more detail at how the students react and learn throughout this challenging and different course.

\subsection{Emotions and resistance}

As described above, this course is substantially different to previous accounting courses that these students have studied during their time at university. The objective, that the students will make sense of the organisational context of management accounting through the study of contemporary research; and through individual and group 
engagement, results in learners experiencing a range of emotions. This is especially apparent in the early weeks of the course, is sensed by the lecturers and was commonly reported within the interviews undertaken for this research. As one alumni student remarked:

"You start the first class and you think 'Am I in the right room? Did I get confused?' I think it is the beginning, (the lecturer) starts talking and you think 'What is (she/he) talking about? Why is (she/he) telling us that? Why is that important' I think the first time you have this negative reaction because you just don't know how to react. You just don't know what it's all about. I think it was my least favourite time because I think I didn’t know. I felt a bit like 'why are they doing this to me?."

Others confess that they first thought the course 'a bit different' , 'really hard', and felt at the beginning 'really lost' , 'shock' , 'overwhelmed', 'struggling', and 'stressed'. A current student explains:

"The fact that it had no numbers kind of frightened me, because I am OK with the number side of things but the non-numerical aspects of finance I struggle with. It was different.”

As noted earlier, Thomson and Bebbington (2004) suggested that students appear to resist different accounting courses that do not fit neatly into their preconceived ideas of 'proper' accounting education. Our research found some interesting indications and evidence of resistance. The negative and emotional reactions experienced by the students do, in some instances, result in resistance in a number of ways. Perhaps one of the most common resistance movements was to complain:

“The natural reaction when you don't understand something and you don't know how to approach it, is you complain about it. To say, it's not me the one that is wrong it's that course that is absolutely wrong."

Complaints could be to friends, but certainly do not stop there. As the senior Administrator interviewed explained:

"Some years there'd been deputations about what it is and some years we've had it through the staff/student committee with them raising it."

Complaining is not the only resistance strategy and another is simply to not engage with the course. One interviewee reported an extreme example of this when their (non-accounting) friend actually transferred to a different course to avoid having to engage with this material. Many students, however, cannot avoid the course in this way, but they still resist by not engaging with the course. As one current student commented:

"I think people switched off right at the start thinking "what have we got ourselves into, this is not accounting'."

One of the academics interviewed gave their perception of how different students engage or do not engage with the course:

"the stronger students love it, they relish it and they become voracious readers and for many of them it is almost a life changing experience and it does make them think about academic subjects, in particular management accounting, in a way that they have probably never thought about before. For the weaker students, they just hate it, resent it and don't really engage in it. What about the majority of students, those in between? I think it will make them better and more reflective accountants." 
Although we do not necessarily agree with the categorisation into 'stronger' and 'weaker' students we have recognised within our own reflections that there is a potential for some students to not engage with the course to the extent that we would hope for. A lack of engagement by students is an important issue and could be a particular issue for such a different course. Therefore, the next section of this paper considers the steps taken within this course to encourage engagement and learning.

\section{The learning process: research, dialogue and assessment}

\subsection{Learning through research}

When referring here to research we do not mean that the students undertake primary research. Rather, we are referring to the process of searching and researching (Freire, 1998) that is essential for all learners, as they develop and transform. On this course the students are allowed the freedom to follow their own research through the reading that they do and so when discussing research many of the students referred to their reading of published research and this is reflected in this section. As an alumni student reflects:

"you have to think a lot and you have to read a lot. The lectures were just a guideline. You would never get the full stop at the end of the lecture."

Individual reading is necessary to grasp the learning objectives identified for the course. Research informed literature is a demanding learning experience and for this course the literature specifically referred to alternative paradigms and perspectives that challenged the more functional 'mainstream' view of accounting that they had previously encountered. This alternative and critical reading around the subject in academic journals was one which caused emotional responses from the students. The initial contact often leads to surprise, as one points out:

"It was a different kind of journal article. It was a bit different. Usually with accounting it has always been about number work so this was the first module where it was theory based. It was a bit of a shock read, to be honest. This is accounting but there are no numbers involved!.”

And:

“The first article I read I didn’t understand where it was going or what it was about but after when I read more I got into it with an open mind.”

It appears common for students to struggle to understand the readings at first, but a number of our interviewees referred to a growing desire to read more widely and follow their own paths through the research:

"It is the type of module you want to research what you like, you want to do wider reading and you want people to read your work and to understand what you are saying."

"I think once I got my head around it, the wider reading, sort of being able to research for yourself and find things that you could understand and use to build a better understanding of these concepts that we talked about rather than having one textbook that maybe you don't actually understand” (...) and the research skills as well and using your initiative to say "this is what I need to find out and how I am I going to do it”. 
These sentiments are a source of great encouragement to us to continue to spend time reflecting on and developing the course. In instances such as this it appears that a weak dialogic approach can enable the development and transformation that we hope for the course.

Certainly, the research required within this course exposes the students to a new, more academic form of writing that is initially problematic and adds to the emotions and resistance mentioned in the earlier section. The students' research requires them to consider different types of academic paper - theoretical, empirical and case studies. A minority of our interviewees suggested that the academic papers that contained case studies were 'easier' and 'more interesting', as compared to the more theoretical papers. This view was not universal, and other students did reflect on how theoretical insights from the papers 'applies to general life really'.

Lea and Street (2006) discuss student writing and literacy in the context of an 'academic literacies' model, which suggests that reading and writing are context specific and will vary between academic communities. Such variety can be difficult for students especially for those from different backgrounds. On this course some students, both native and non-native English students, have struggled to engage with some of the readings on our course and this is not unusual for students shifting into higher education. Simply requiring reading would not be an appropriate way to encourage the learning desired within the course. Essential reading alone will not encourage the critical and enquiring learning sought. One of the strongest themes from the interviews with students is the role that interaction and dialogue play in the learning experience of the students.

\subsection{Learning through dialogue/interaction}

Fundamental to overcoming the emotional responses and subsequent resistance is a consistent encouragement to interact, which enables a constructive engagement. This dialogue/interaction was encouraged in lectures, tutorials, debates, and in other support (such as office hours) offered to the students from the very beginning of the course. It is worth pausing here to discuss what we mean by encouraging engagement. Throughout the course questions and problems were posed to students, as advocated by Freire (1993). We feel, however, that in order to encourage engagement it is not appropriate to demand answers. Such a confrontational approach would not engender engagement, discussion and dialogue. Wherever possible time and space is provided for students to consider and discuss the question or problem that has been posed and to start small group discussions with fellow students. It is difficult to demonstrate whether a full dialogic engagement occurs, but on reflection we do perceive greater levels of engagement, discussion and dialogue than we find on other courses. Further, we also find that over the duration of the course more and more of the students actively engage and discuss the questions posed. Interaction with the academics was frequently mentioned as useful, as an alumni student explains:

"(the lecturer) asked us a lot of questions in the lectures, asked us to participate and (she/he) would give us some time to discuss and (she/he) asked what have you done in the placement and how that related with the theories that we have studied, and that did help. That helped us to participate and understand the theories better." 
Also a current student confirms "the lectures were more interactive and our opinions were asked for a lot more than there were in other lectures" and another current student admits "I think it's better to be interactive than just to sit back and try to take information in”. Such an interactive conduct during both terms of the course develops an ongoing relational process of common effort and respect. Numerous interviewees commented on the different, more interactive nature of the lectures for this module.

Interaction and dialogue were also strongly encouraged in tutorials and office hours. A number of interviewees identified the support offered by lecturers, particularly the effort to understand each learner's individual views, as important:

"I think the lecture was structured in a way that you felt valued, I think that sounds silly but you felt like you wanted to go to the lectures because you kind of had respect for the lecturer because you know that if you had any problems with the course, you could go and talk to the lecturer which I think is very important. So you want to do well even if you find it very difficult, you know, we had support there which really motivated me to try hard and the way the lecture was structured, it suited the module's objectives. It couldn't really be rigid because it wouldn't really help us achieve what we were meant to do (...) the lecturer was more like a friend, not even a friend but someone you had respect for."

Progressively during the term students engage with the material and learning objectives and often seek to communicate their thoughts to gain confidence and support, as an alumni student remembers:
"Actually, take for instance, when I was doing my second project/assignment. I had a plan, I wrote it down and I went to see (the lecturer) and I said 'this is my understanding of this topic and am I on the right track?' She/he would not tell you 'yes, you are wrong, or not'. She/he would try and make you think if you are on the right track. She/he would ask leading questions making you think that you've made the decision and you'd say 'oh yes, this point is right'. And if you were wrong she/he would guide you to the right track without telling you 'you should do this, or you should do this'. She/he's leading you and I think that's really good.”

During the first term students were asked to read an academic paper in advance of the tutorials and then it was discussed in small informal groups. The students were asked to brainstorm on the topic of the paper, as an alumni student remembers:

"the lecturer gives us some time and then (she/he) goes through each group and talked to group members and that kind of forced us to think. Because, you know she/he is coming to us so she/he is going to ask questions and she/he is going to expect something from us and that helps."

And although attendance records are not kept strictly most students prefer those classes, as a current student reflects "I think it is best if we stick to groups of four or five and try and discuss".

During the second term of the course, assessed debates sustain the engagement with the learning objectives. In groups of four or five, students are invited to read a case study research paper and pursue a coherent view on a fundamental question by Hopwood (1974) “Do controls lead to control?” The preparation of each group involves references and arguments found in relevant academic literature. Then two different groups meet during tutorial hours and discuss their view. Often both groups pursue a similar perspective although the structure and analysis of their argument can be informed from 
different resources. Groups are encouraged to interact and cooperate, as a current student explains:

"we split up research because there are lots of journals to read from different areas so we were able to do more reading as a group rather than if I did it on my own.”

Debating is a new experience for most of the students and although they often feel 'quite nervous about it', they soon engage and realise the learning potential, as an alumni student explains:

"I found the debate quite interesting because we had a group of students contributing ideas of one topic and then you have two groups of students debating about they what they think (...) from that debate I think everyone get a lot of new knowledge based on what they have already got."

Learning expands from academic to general skills for all students, as a current student reflected:

"in the debates we'd got one member in the groups, she was an international student and she wasn't really confident in the debate process so we tried to help her. She was happy with what we were talking about and we tried to help her as best as we could so that she could contribute in the debate, which I think it is another skill because you have got to understand what other people's strengths and weaknesses are.”

In feedback from the class a view that is commonly communicated is reflected in the words of another current student: "I think I really liked that, it improved a side of me (..) being able to look at different points and having one view”.

Clearly interaction between students during the term enhances learning, with a deeper engagement and understanding. Often students discuss their reading with their friends, as an alumni student remembered:

"during the exam and during the essay time, we talked to each other about our understanding on the topics so we could have a better understanding when combining each others views."

And

\begin{abstract}
"It really felt very interactive and there was a lot of discussion between class mates, between group members... In OCMA it made you want to discuss it with other people, like we always asked each other 'I don't understand this side' or 'what do you think of certain thing?.. It did create interaction which in other subjects we didn't do at all."
\end{abstract}

The interaction encouraged and experienced on the course are important in enabling learning. The dialogue between the lecturers and learners and, equally importantly, among learners enabled reflection and further investigation that enabled greater engagement.

\title{
6.3 Learning through assessment
}

The literature identifies leaving space and choice in the course as important. On this course this is primarily done through the assessments (see Yorke, 2003; Gibbs, 1995, Race, 2005). In total there are four assessments and as far as possible students are encouraged to make their own choices about how each assessment should be approached. 
For all assessments the students are encouraged to develop their own individual view that must be informed from the literature and theory. A very wide ranging reading list is provided to the students, but they are further encouraged to search more broadly for theoretical and empirical insights into the issues raised by the assessments. From our interviews a number of comments were made as to the 'openness', 'freedom' and 'broadness' of the possibilities for the students to stamp their individuality upon the assessed work.

In terms of assessment, the two essays and the debate are widely perceived as more relevant, while a three hour closed book exam at the end of the course is seen as less useful, as a current student comments

\begin{abstract}
"I don't really think you can reflect what OCMA is trying to achieve in an exam because I think the aim is to understand what people have found from their research and to try and apply that to your own situation which in an exam you've not got the ability to go and look at the research. You can have learnt it beforehand but no, you can't take it all in with you."
\end{abstract}

The value of the debate as a learning tool has already been discussed in the previous section, as it is one way in which interaction and dialogue are encouraged. The other coursework essays were also identified as really important learning experiences, although this was valuable in a variety of ways to the different students. For many of our interviewees the process of research undertaken in completing the first assignment was a crucial element to the students engaging with the course and overcoming some of the initial resistance to the course. This process is exemplified in the following two quotes:

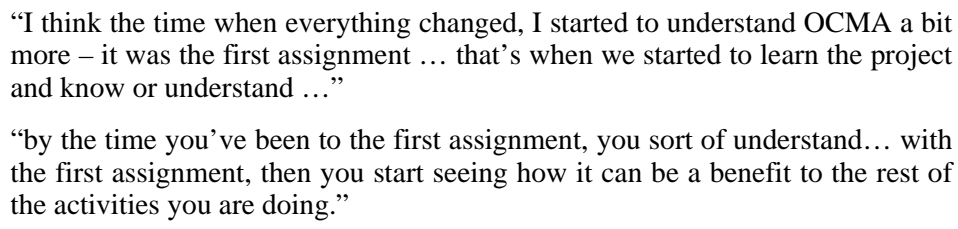

"I think the time when everything changed, I started to understand OCMA a bit more - it was the first assignment ... that's when we started to learn the project and know or understand ..."

"by the time you've been to the first assignment, you sort of understand... with the first assignment, then you start seeing how it can be a benefit to the rest of the activities you are doing."

Some of the other interviewees identified the feedback from their first assessment as a valuable learning tool. For some the feedback provided reassurance that they "were grasping the material and whether I was interpreting it right... when I got the mark back it was a good mark so I thought 'well I can't be doing that badly'”. For others the feedback identified aspects of the student's work where they had failed to engage with the materials sufficiently and this is nicely demonstrated by one student:

\begin{abstract}
"I think the first was my grade for the first coursework. Obviously $64 \%$ was OK. I thought I'd done a great piece of work. I thought 'this is excellent' and I thought I'd get something like 75 or $80 \%$... So I've looked at other people's coursework after that I realised that their approach is very different from what I had done... Actually people who had done well in their coursework, the link was quite clear and you could see what they had done which, obviously that was absent from mine."
\end{abstract}

This quotation is worth reflecting upon a little further. First, it demonstrates that we have to award a specific \% mark to each assessment and whilst the marks are not awarded for technical accounting prowess the HE system requires a mark. Here the marks are awarded as against the main three learning objectives, as reported earlier. This is an instance where the constraints of the HE system within which we operate move us away from enabling a more dialogic learning process. Certainly, such formal assessment is not 
something that Freire $(1993,1998)$ discusses as being important to such a process. The potential for the assessment mark to be seen in an instrumental way are also evident. A question remains here as to whether such formal assessment and marking is really enabling the students to be more human.

This course includes four different assessments that are spaced throughout the academic year. Students specifically identified the first coursework and the debate as important learning events within the course. The interviewees felt that these assessments in particular enable engagement and had important roles to play in the interaction and dialogue identified in the previous section. The next section discusses how this course also develops transferable and professional skills.

\section{Developing and transforming learners}

A key element of the course is to motivate students to think and construct an informed view on the usefulness of accounting in organisations, and the role of accountants in the potential use of control systems and patterns of accountability in their organisational context. Such a motivation develops both their academic abilities to gather informed insights through critical analysis of research led literature, as well as developing and transforming them as individuals. In some instances the developments relate to academic skills, others relate to skills that may be of value professionally and others still that can be valuable in life more generally. One key skill that was identified by a number of interviewees related to thinking. Specifically, the interviewees suggested that the course helped them 'broaden' and 'develop' their thinking through their exposure to different perspectives and "it takes you out of numbers and into the context of how those numbers apply”. One alumni interviewee explained how the critical-thinking skills developed on the course have helped in the workplace:

"I found critical-thinking skills are really important in the workplace, in professional environments. They always tell you that you have to be very sceptical about your clients on certain things and you have to think broadly but this skill cannot be obtained in a year.”

Communication skills were also identified by the students interviewed as being developed within the course. Firstly, the reading of academic journal articles was recognised as a skill in its own right. As one student remembers:

\footnotetext{
"the journals they were completely different, like nothing I had seen before. I thought I could give myself half an hour to read something and then get it, but NO! I spent days and nights on one journal and I thought this can't happen and so it was a skill I had to learn, how to read journals.”
}

Others noted how the reading had improved their 'comprehension' and 'vocabulary' and this had a direct effect on their own writing style. A number of students suggested that over the duration of the course their writing style had 'improved' and how they used this skill to improve their academic performance on other modules.

A number of students identified the debate as an important learning experience, as "you have to be in a debate in your life later on". This is not to say that the students felt that they would be involved in a formal debate, but that the debating skills could be used in other settings where the issues were contested. The ability to communicate orally in many different circumstances is a valuable skill, as a current student reflects: 
"It's like a discussion. I still think it's the communication skills that you need that are really important when you go to interviews and in work as well, which isn't really a skill that you pick up from anywhere else."

In all of the assessments for this course, both written and in the debate, an explicitly required skill is the ability to develop an informed and supported argument and some students identified this and the value it added to other courses studied:

"I've really noticed that especially the way I develop an argument so that's helped with Law as well."

This view was reiterated by one of the academics interviewed who stated:

“you're actually helping them to learn how to present an argument and how to defend it. And so I think it is extremely good training for success in the workplace because those kinds of presentations, for being able to defend your point of view.”

One of the written assignments and one section of the exam paper require students to analyse a case study and as one student expressed it:

"One of the things that really makes a difference is how to do a case study, how to approach a case study.”

One student went further and recognised that such case study skills will be valuable to them in the future as they were aware that this is required by some professional accountancy bodies in their own assessments. This was also reiterated by one of the academics interviewed who had previously taught on the module:

"Complex problem solving amidst ambiguity and partial knowledge (these skills are particularly useful in CIMAs strategic level subjects and the TOPCIMA final case study).”

More generally, an alumni student also mentioned how the course has helped them in their subsequent employment:

"Definitely managerial skills, if you can get the numbers right very few people will be able to see the big picture. Maybe you don't necessarily consciously apply the theories by name, by author or whatever, but you still have that in the back of your mind, for example, when I was doing analysis for the cross-sales one of the things that I noticed from the other people as the risk factor was the problem, how these influences, the profitability of the business and how the bonuses affect the profitability, therefore, people will never agree on anything. You don't ask them to because they won't. One person having less and the other person having more. There's a no win, win situation so it will have to lead to a compromise or lead to somebody from the top saying ' $\mathrm{OK}$ this is it end of the story. And it's one of the things that I put forward and I think that's when I realised straight away applying skills that I learned at OCMA, which is maybe not just about managing people but managing a process, taking into account the people involved. I think that's one of the main things.”

Students on this course are required to demonstrate a different set of skills to those, more numerical, skills that they are assessed on in their other accounting courses and, as the above quote identifies, this can enable students to develop skills that will be of value in future, possibly managerial, careers. As two of the academics interviewed suggested:

"I think OCMA enables students to really be more effective in their employment by understanding that decisions are not always (or are perhaps rarely) made for rational economic reasons alone.” 
“To get on the Board you've got to be a politician, because you don't get to Board level in major organisations without knowing how to play the organisational politics game. Also you need to have a much more rounded set of skills, you need the kind of soft skills".

A number of the interviewees did reflect upon how their development and transformation through the course had affected their world view. Such reflections were usually related to how the alternative perspectives and theoretical lenses that they had encountered on the course had, they thought, given them a means of understanding events that they previously did not have. For example, one such student referred to how events in Burma were 'highlighted' more as a result of his/her changed perspective.

\section{Discussion}

This paper reports upon a study of a research-tutored undergraduate accounting course. It challenges the students in ways that the other courses on their degree programme do not. From the outset of the course it is made abundantly clear that the course is not about the calculation of accounting techniques, but will require students to explore and research the organisational context of management accounting. Such a movement echoes Freire's (1993, 1994) call for departure from 'banking' education to a more dialogic learning that aids self-transformation and development. It appears that our interviewees did indeed recognise this, as one of the alumni students explained

\footnotetext{
"I started to see accounting as just not numbers. I started thinking of it as a twoway process: one is the technical side and the other one is the human side. (..) before I thought I will have to work the formula and that is the end of the story. Now I can see why that formula, even though it is OK, it wouldn't work. It doesn't matter how technically advanced I can be I still need to think of the human side.”
}

The acceptance of such a different course is not immediate and the interviewees reported that the course created an emotional response, especially at the start of the academic year, and the reaction of some students to this was to try to resist it. The course was requiring students to move out of their comfort zone and develop different skills. This is again related to the omission of calculative techniques and the requirement for communication, debate, dialogue and the development of arguments. The students find this course difficult and time-consuming, but also rewarding and in some cases it can make a dramatic difference to their outlook on life, business and accounting. In the heart of such response other accounting educationalists (see Boyce, 2004; Coulson and Thomson, 2006; Tinker and Koutsoumadi, 1997) have identified a range of challenges that are either systemic in higher education or embedded in the relations of accounting education with the accounting profession.

We hope that this paper has identified that such critical, research-tutored, accounting education is a powerful educational tool that complements and augments the students' more traditional accounting education. We suggest that taking steps on the continuum from banking towards dialogic education is meaningful and necessary for accounting education. In the light of the research - teaching nexus (see Griffiths, 2004; Healey, 2005; Jenkins et al., 2007) our paper aligns with the view that in the process of learning both educator and students are experiencing a self transformation that is sourced in the interplay of two integral elements of the learning process that of teaching and 
researching. That involves the creation of the possibilities of the production of knowledge, i.e., teaching and also the exploration the countless possibilities of knowledge with methodical curiosity and reflection, i.e., research.

It is also the case that such a course presents a different experience for the academic staff involved. We engage with Freire's (1998) view that acknowledging the unfinished and incomplete condition of human nature a permanent learning process includes both teachers and students in an ongoing dialogic learning encounter. Firstly, the greater interaction between the lecturers and the students, as identified by the students above, provides a better learning experience for the lecturer. Also the content of the course is such that it has other benefits, as two of the academics interviewed commented:

"It was especially fulfilling to teach material that was (a) research led, (b) linked what students had learned in prior subjects to their practical industry experience, (c) encouraged students to engage with academic literature, books and case studies, and (d) resulted in many high quality discussions and written coursework."

"Yes, because for a start it encouraged me to keep up-to-date with my reading ... regularly going online and seeing what's come out in Management Accounting Research or AOS? and so on.”

Finally, it is important to note that there are a number of limitations to this study, but perhaps first and foremost it must be recognised that only a sample of OCMA students agreed to share their time with us for an interview. Those that agreed to participate were self-selecting and so may have a biased view of the course. They may have been willing to participate in this research with us because they engaged in a particular way which others, who did not come forward, may not have done. This does raise questions as to how well this study reflects the views of the whole population of students that take this course. To mitigate this we have attempted to include views obtained through other mechanisms such as staff: student committees and the formal university feedback systems. What we do feel able to say, however, is that for some students this research-tutored, critical course has proved a valuable learning experience, which has helped them to develop in ways that may be of use to them in their futures.

\section{References}

Argyris, C. (1969) 'Selections from the impact of budgets on people', Organizations: Structure and Behavior, Vol. 1, p.282.

Biggs, J. (2003) Teaching for Quality Learning at University, 2nd ed., Open University Press, UK.

Boyce, G. (2004) 'Critical accounting education: teaching and learning outside the circle', Critical Perspectives on Accounting, Vol. 15, No. 4, pp.565-586.

Brew, A. (2003) 'Teaching and research: new relationships and their implications for inquiry-based teaching and learning in higher education', Higher Education Research and Development, Vol. 22, No. 1, pp.3-18.

Bruns, W. and DeCoster, D. (1969) Accounting and its Behavioural Implications, McGrawhill Inc., USA.

Burch, T. (2008) 'Teaching and learning accounting with overseas students', People and Place, Vol. 16, No. 1, pp.12-20.

Caplan, E. (1966) 'Behavioural assumptions of management accounting', The Accounting Review, Vol. 41, No. 3, pp.496-509. 
Chua, W. (1986) 'Radical developments in accounting thought', The Accounting Review, Vol. LXI, No. 4, pp.601-632.

Cooper, D. and Hopper, T. (1987) 'Critical studies in accounting', Accounting, Organisations and Society, Vol. 12, No. 5, pp.407-414.

Cottrell, S. (2005) Critical Thinking Skills, Developing Effective Analysis and Argument, Palgrave McMillan, Basingstoke.

Coulson, A. and Thomson, I. (2006) 'Accounting and sustainability, encouraging a dialogical approach; integrating learning activities, delivery mechanisms and assessment strategies', Accounting Education, Vol. 15, No. 3, pp.261-273.

Cousin, G. (2009) Researching Learning in Higher Education: An Introduction to Contemporary Methods and Approaches, Routledge, London.

Cuganesan, S., Gibson, R. and Petty, R. (1997) 'Exploring accounting education's enabling possibilities, an analysis of a management accounting text', Accounting, Auditing and Accountability Journal, Vol. 10, No. 3, pp.432-453.

Day, M., Kaidonis, M. and Perrin, R. (2003) 'Reflexivity in learning critical accounting: implications for teaching and its research nexus', Critical Perspectives on Accounting, Vol. 14, No. 5, pp.597-614.

Dillard, J.F. (1991) 'Accounting as a critical social science', Accounting, Auditing and Accountability Journal, Vol. 4, No. 1, pp.8-28.

Freire, P. (1993) Pedagogy of the Oppressed, Penguin, London.

Freire, P. (1998) Pedagogy of Freedom: Ethics, Democracy, and Civil Courage, Rowman \& Littlefield, Oxford.

Gibbs, G. (1995) Improving Student Learning Through Assessment and Evaluation, Centre for Staff Development, Oxford Brooks University, UK.

Griffiths, R. (2004) 'Knowledge production and the research-teaching nexus: the case of the built environment disciplines', Studies in Higher Education, Vol. 29, No. 6, pp.709-726.

Hattie, J. and Marsh, H.W. (1996) 'The relationship between research and teaching: a meta analysis', Review of Educational Research, Winter, Vol. 66, No. 4, pp.507-542.

Healey, M. (2005) 'Linking research and teaching: exploring disciplinary spaces and the role of inquiry-based learning', in Barnett, R. (Ed.): Reshaping the University: New Relationships between Research, Scholarship and Teaching, McGraw Hill/Open University Press, UK.

Hopwood, A. (1974) Accounting and Human Behaviour, Prentice Hall Contemporary Topics in Accounting, Prentice Hall Inc., New Jersey.

Hopwood, A.G. (1983) 'On trying to study accounting in the contexts in which it operates', Accounting, Organizations and Society, Vol. 8, No. 2, pp.287-305.

Howieson, B. (2003) 'Accounting practice in the new millennium: is accounting education ready to meet the challenge?’, The British Accounting Review, Vol. 35, No. 2, pp.69-103.

James, K. (2008) 'A critical theory and postmodernist approach to the teaching of accounting theory', Critical Perspectives on Accounting, Vol. 19, No. 5, pp.643-676.

Jenkins, A. (2004) A Guide to the Research Evidence on Teaching - Research Relations, Higher Education Academy, York.

Jenkins, A., Healey, M. and Zetter, R. (2007) Linking Teaching and Research in Disciplines and Departments, Higher Education Academy, York.

Kaidonis, M. (2004) 'Teaching and learning critical accounting using media texts as reflexive devices: conditions for transformative action or reinforcing the status quo?', Critical Perspectives on Accounting, Vol. 15, No. 4, pp.667-673.

Laughlin, R. (1987) 'Accounting systems in organisational contexts: a case for critical accounting', Accounting, Organisations and Society, Vol. 12, No. 5, pp.479-502.

Lea, M.R. and Street, B.V. (2006) 'The 'academic literacies' model: theory and applications', Theory and Practice, Vol. 45, No. 4, pp.368-377. 
Low, M., Davey, H. and Hooper, K. (2008) 'Accounting scandals, ethical dilemmas and educational challenges', Critical Perspectives on Accounting, Vol. 19, No. 2, pp.222-254.

Lowe, E. (1970) 'Budgetary control, an evaluation in a wider managerial perspective', Accountancy, November, pp.764-769.

Lucas, U. (2008) 'Being 'pulled up short': creating moments of surprise and possibility in accounting education', Critical Perspectives on Accounting, Vol. 19, No. 3, pp.383-403.

Malcolm, M. (2008) 'Research-teaching linkages: enhancing graduate attributes', Business, Management, Accountancy and Finance, The Quality Assurance Agency for Higher Education, UK.

McPhail, K. (2004) 'An emotional response to the state of accounting education: developing accounting students' emotional intelligence', Critical Perspectives on Accounting, Vol. 15, No. 4, pp.629-648.

Moon, J. (2004) A Handbook of Reflective and Experiential Learning, Theory and Practice, Routledge Falmer, UK.

Norton, L.S. (2009) Action Research in Teaching \& Learning: A Practical Guide to Conducting Pedagogical Research in Universities, Routledge, London.

Parker, L.D. (2001) 'Back to the future: the broadening accounting trajectory', British Accounting Review, Vol. 33, No. 4, pp.421-453.

Race, P. (2005) Making Learning Happen, Sage Publications Ltd., UK.

Robertson, J. and Bond, C. (2005) 'The research/teaching relation: a view from the edge', Higher Education, Vol. 50, No. 3, pp.509-535.

Saravanamuthu, K. (2004) 'Gold-collarism in the academy: the dilemma in transforming bean counters into knowledge consultants', Critical Perspectives on Accounting, Vol. 15, No. 4, pp.587-607.

Thomson, I. and Bebbington, J. (2004) 'It doesn't matter what you teach?', Critical Perspectives on Accounting, Vol. 15, No. 4, pp.609-628.

Tinker, T. (1985) Paper Prophets, Praeger, New York.

Tinker, T. and Koutsoumadi, A. (1997) 'A mind is a wonderful thing to waste: 'think like a commodity, become a CPA', Accounting, Auditing and Accountability Journal, Vol. 10, No. 3, pp.454-467.

Yorke, M. (2003) 'Formative assessment in higher education: moves towards theory and the enhancement of pedagogic practice', Higher Education, Vol. 45, No. 4, pp.477-501.

\section{Notes}

1 In effect the 'current' students had finished the course, as all assessments had been marked and were with the appropriate university departments. Further all assessments are blind marked and candidate numbers were not taken from our participants.

2 The senior administrator was the director of undergraduate studies and managed the undergraduate office. This office has responsibilities for admissions, assessments, placements, and this administrator chaired the undergraduate management team and the undergraduate staff student committee within the business school. 